\title{
What could be influencing older Ghanaians outpatient care utilization rate?
}

\author{
Candidus C. Nwakasi ${ }^{1}$, J. Scott Brown ${ }^{1}$ and Phillip Anyanwu ${ }^{2}$ \\ Ghana Med J 2019; 53(3): 217-225 doi: http://dx.doi.org/10.4314/gmj.v53i3.6
}

\author{
${ }^{1}$ Department of Sociology and Gerontology, Miami University, Ohio, USA \\ ${ }^{2}$ Faculty of Medicine, School of Public Health, Imperial College, London, United Kingdom
}

Corresponding author: Candidus C. Nwakasi
Conflict of interest: None declared

E-mail: nwakascc@,MiamiOH.edu

\section{SUMMARY}

Objectives: Ghana's population is rapidly aging and there may be healthcare access and utilization issues. This study investigates some of the issues that may influence outpatient care utilization rate among older Ghanaians. Methods: Cross-sectional wave 1 (2007-2010) data from WHO's Study on Global Ageing and Adult Health are used, and a sample of 1408 are analyzed. After multiple imputations of missing values, a negative binomial regression model is used to identify the association between outpatient care utilization rate and lifestyle activities. Results: The rate of outpatient care utilization is negatively associated with the rate of eating vegetables $(\beta=0.0830$, $\mathrm{p}<.001)$, fruits $(\beta=0.0033, \mathrm{p}<.05)$, moderate-exercise $(\beta=0.4010, \mathrm{p}<.001)$, moderate-work $(\beta=0.2049, \mathrm{p}<.001)$, walking/biking $(\beta=0.0436, \mathrm{p}<.001)$, and positively associated with leisure hours $((\beta=0.0194, \mathrm{p}<.001)$. Conclusion: To promote better aging situations of older adults in Ghana, poverty and poor education should be addressed as potential barriers to healthcare access. There is a need for policies that encourage healthier lifestyles for older Ghanaian's health.

Keywords: Africa, aging, lifestyle, healthcare, quality of life Funding: The study was self-funded by the authors

\section{INTRODUCTION}

Maintaining optimum health and healthcare utilization are persistent issues among older Ghanaians ${ }^{1,2}$, and with only $33 \%$ of Ghana's total population covered by the country's health insurance scheme, it is evident that healthcare access is a problem among poor older Ghanaians. ${ }^{3}$ Although there is inequity in access to the country's health insurance scheme ${ }^{4,5,6}$, some researchers also argue that the scheme is not sustainable because of issues such as ineffective organization, broad free benefits package, poor health facilities, and scarce health workers. $^{7}$

It is assumed that policy makers and other stakeholders will benefit from studies that identify factors that influence outpatient care utilization rates among older Ghanaians. The study findings may inform health promotion campaigns and ways to reduce the current burden on access to healthcare among the increasing population of older adults in Ghana. Demographic studies indicate that the global population is aging. By 2050, there may be about 2 billion people aged 60 years and above, and $80 \%$ of this particular age group will be found in low and middle-income countries. ${ }^{8}$ Some studies indicate that while the population of the 60+ age group in Africa is expected to rise from 45.7 million to 182.6 million, West Africa will have the largest number of the $60+$ age group and most will be in Nigeria and Ghana. ${ }^{9}$ For example, the 2010 census in Ghana showed that there was a $770 \%$ increase in the population of its older people (age 60+) from 213,477 in 1960 to $1,643,381$ in $2010 .{ }^{10}$ Therefore, there is evidence that Ghana's young population is rapidly aging and this may have social and health implications.

Population aging in Ghana is likely to present a nationwide challenge as the country seems unprepared for the demands of an unprecedented rapidly changing demography. ${ }^{8,10}$ To compound this growing policy issue is the dearth of evidence based aging related studies in Ghana. ${ }^{10,11}$ Furthermore, because older age in Ghana is associated with increased risk of non-communicable diseases, healthcare issues are worsened by Ghana's limited or missing social security coverage and economic underdevelopment. ${ }^{11,12}$ Most older people in Ghana reside in the rural areas; and the poor potable water, sanitation, and housing conditions increase the risk of poor health outcomes for these older adults. ${ }^{2,8}$ 
Relating to rural dwelling older Ghanaians, their odds of having chronic non-communicable diseases is twice the odds of those in urban area, and these older adults in rural regions of Ghana depend on unorthodox medical practices for healthcare support. ${ }^{5,13}$ Since the risk of noncommunicable diseases tends to increase with age, modifying lifestyle activities like nutritional and physical activities may play important roles to reduce the increasing burden of chronic diseases among older adults in Ghana. ${ }^{14}$ For example, improving fruit and vegetables consumption among adults may prevent cancer ${ }^{15}$ and cardiovascular diseases ${ }^{16}$, and older adults and their families can benefit from preventing the high medical cost that results from sedentary lifestyle. ${ }^{17}$

Furthermore, proper diets (e.g., fruits and vegetables intake) and physical exercise help to reduce the rate at which a person's functionality declines with age, hence, delaying the onset of disability at older age. ${ }^{18,19,20}$ This is perhaps, linked to the low risk of chronic diseases like heart diseases, obesity, osteoporosis, diabetes, and cancer associated with healthy eating and physical activity. ${ }^{18,21,22}$ There are scarce studies about nutrition and exercise amongst older Ghanaians. However, a study on adult Ghanaian lifestyle behavior showed that alcohol consumption was on the increase, and only a small number of adults adhered to the recommended daily fruits and vegetables servings. ${ }^{23}$ Another study found that malnutrition is a problem faced by older adults in some regions of Northern Ghana. ${ }^{24}$

Malnutrition impedes the chances of improved health outcomes for older adults who should be engaging in optimal lifestyle activities. On the other hand, because older Ghanaians can rarely afford to own cars ${ }^{8}$, walking is their main means of transportation. Although this may be an indication of poverty, it may also be a source of physical exercise that helps to improve their health outcomes.

\section{Theoretical framework}

The study is based on the behavioral model for vulnerable populations ${ }^{25,26,27}$. According to the model, health behaviors such as healthcare utilization is a function of a person's predisposition, factors that enable or hinder utilization, and a person's need for care ${ }^{25}$. Examples of predisposing factors are sociodemographic factors such as age, gender, and marital status; enabling factors may be education/literacy, income, lifestyle activities/practices, living conditions; and need factors may be perceived health problem or health status. Therefore, it is assumed that sociodemographic and socioeconomic factors, and health status, are major influencing factors of healthcare utilization of older Ghanaians. The study's focus is on lifestyle activities as enabling factors that influence outpatient care utilization.
Additionally, the study's significance is based on the scarcity of aging related studies, especially on lifestyle activities that predict healthcare utilization in Ghana, and Africa as a whole. In an effort to fill some of the identified gaps, this study explores the association between lifestyle activities (e.g., fruit intake, vegetable intake, walking, biking, sedentary lifestyle, physical activities) and outpatient care utilization rate. The study hypotheses are the following among older Ghanaians: 1) regular eating of fruits and vegetables is expected to have a negative relationship with outpatient/home care use; 2) engaging in physical activities like moderate exercise, moderate work, walking and biking will be negatively associated with outpatient care utilization rate; 3) sitting down for long periods is expected to be positively associated with outpatient care use.

\section{METHODS}

\section{Data}

The WHO Study on Global Ageing and Adult Health (WHO SAGE) Wave 1 cross-sectional data is used, and the response rate for the multi-stage probability sampling is $81 \%$ for Ghana. ${ }^{28}$ The wave 1 data conducted from 2007 to 2010 is a follow-up of wave 0 study of four countries (Ghana, India, Mexico and Russia). WHO SAGE is a longitudinal study that began with wave 0 ; the wave 2 phase has been conducted but the dataset is yet to be made available. For all countries, households were classified into 50+ household or 18-49 household. For Ghana, the number of respondents is $5110,53 \%$ male, $47 \%$ female, and the average age is 60.19 years (see "participants" subsection for more about sample description). The individual questionnaire used for the study is available at https://www.who.int/healthinfo/sage/en/ .

\section{Ethical Approval}

Ethical approval was not required because the study is a secondary analysis using public use data from World Health Organization through Inter-University Consortium for Political and Social Research.

\section{Measures \\ Outcome Variable}

Care use rate. The outcome variable investigated in the study is the number of times an individual used outpatient care or home medical care that did not involve overnight stay at a healthcare facility. The question asked was "the number of times in the past 12 months the respondent received care at a hospital, health center, clinic, private office, or at home from a healthcare provider (health worker)". This study expects that increased use of outpatient care may be an indication of poor health; hence, seeks to model a relationship between this outcome variable (frequency of outpatient care/care at home) to specified explanatory variables. 


\section{Independent Variables}

Because the study is interested in the relationship between outpatient care utilization rate and some lifestyle activities, the independent variables in the study are: age, sex, educational level, number of fruit servings per day, number of vegetable servings per day, leisure hours per day (hours spent reclining or sitting but not sleeping), hours spent doing moderate work per day, hours spent doing moderate exercise per day, and the number of hours spent walking or biking per day. The educational level variable, which is an ordinal variable, ranged from no formal education (lowest level) to post-graduate degree (highest level).

\section{Lifestyle activities}

The variables of interest are number of fruit servings per day, number of vegetable servings per day, leisure hours per day (hours spent reclining or sitting but not sleeping), if participants engage in walking/biking, moderate work activities, and moderate physical fitness activities or exercise. The first 3 predictors are continuous variables while the last 3 are categorical variables. The categorical variables are dichotomized (i.e., coded as yes or no) while the not applicable and don't know responses are coded as missing. The choice of variable is guided by

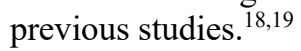

\section{Covariates}

Age was restricted to $60+$ years in the study because Ghana's retirement age is 60 years. Gender was either male or female, marital status included those who are: never married, currently married, cohabitating, sepa$\mathrm{rated} /$ divorced, widowed. The marital status values were coded as partner or no partner. The education level variable contained those with: no formal education, less than primary school, completed primary school, secondary school, high school (or equivalent), college/university completed, and post-graduate degree. No formal education to completed primary school was merged to be low education level while the rest were merged to form high education level. The variable, if participant had enough money to meet needs included those who do completely, mostly, moderately, a little, and none at all. The first 3 values were merged to mean yes while the last 2 were merged to mean no. Thus, responses in the categorical covariates were dichotomized. These variables are controlled in the analyses because studies have shown that socio-economic and demographic factors, health, and quality of life may predict healthcare access of vulnerable population groups such as older Ghanaians. ${ }^{25,26,27}$

\section{Conceptual Model}

Sociodemographic factors like age, gender, relationship status, place of residence, and socioeconomic factors such as educational and poverty level are expected to have a relationship with a person's outpatient care utilization rate. It is also assumed that health status and a person's need for care will be associated with the rate of outpatient care utilization. The predictors of interest are regarded as lifestyle activities in the study. In the model, it is expected that increased fruits and vegetable servings will reduce outpatient care utilization rate. It is also assumed that participating in moderate physical exercise, moderate work, and taking a walk or biking will reduce the rate of outpatient care utilization rate. See figure 1 for the study's conceptual model.

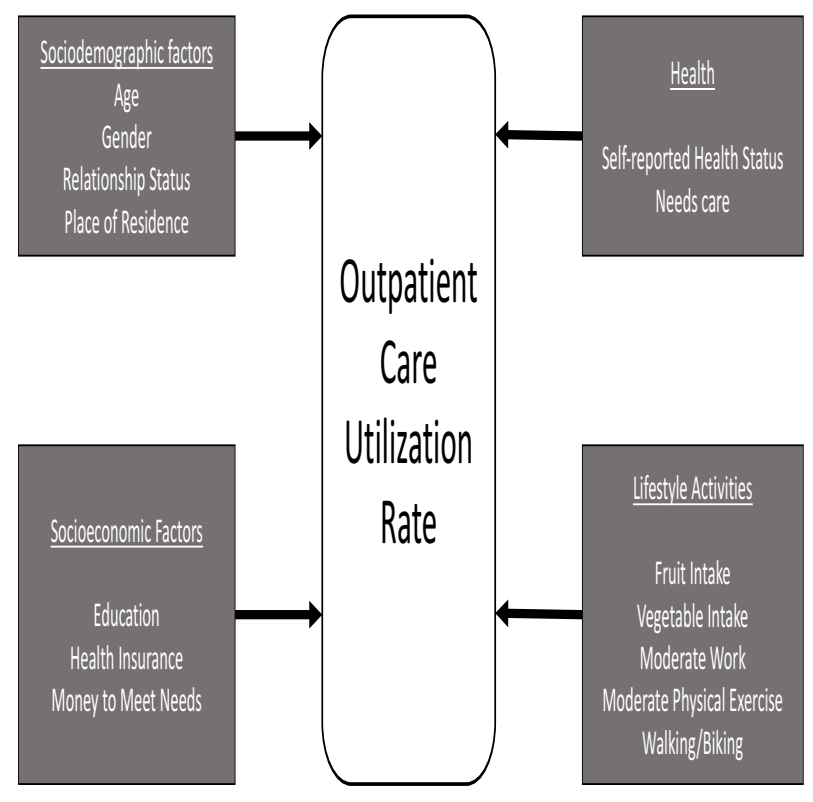

Figure 1 Conceptual Model with Outpatient Care Utilization Rate as Outcome Variable

\section{Statistical Analysis}

Data cleaning and analysis were conducted using SAS (v9.4). The outcome variable is a discrete count variable with a Poisson distribution. A generalized linear model involving negative binomial regression was used instead of Poisson regression due to the issue of over-dispersion observed. ${ }^{18,19}$ However, before the regression model was fitted there was a $46.7 \%$ level of missing values of the outcome variable. Multiple imputation (MI) method was used to address the missing data. This is recommended for missing at random assumptions ${ }^{30,31,32}$ and MI can result in statistical inference that represent the uncertainty related to the missing data estimations. ${ }^{33}$ 
Additionally, MI is robust enough to produce satisfactory results for small sample size and high missing data of up to $50 \%$ fraction of missing. ${ }^{33,34}$ The fully conditional statement approach included in the MI is deemed appropriate for the count variable with the missing values as this approach does not assume that there is a joint distribution for variables of interest. ${ }^{35}$ Because there was a $46.7 \%$ proportion of missing values, 47 imputations were done to increase the relative efficiency of the effect estimates. ${ }^{31}$

\section{Participants}

The minimum age of respondents in the study was 60 years, while the average age was 71.26 (weighted 71.23).
There are 647 males (45.95\%, weighted $49.31 \%)$ and 761 females $(54.05 \%$, weighted 50.69$)$; 663 older adults have partners $(47.09 \%$, weighted $52.56 \%)$ while 745 are without partners $(52.91 \%$, weighted $47.44 \%)$. The number of those in rural areas is $801(56.89 \%$, weighted $56.43 \%)$ and those in urban areas is $607(43.11 \%$, weighted $43.57 \%)$. There is wide contrast between those who are educated and those are not; 1124 have low education level $(79.83 \%$, weighted $77.38 \%)$ and only 284 have high education level (20.17\%, weighted $22.62 \%)$. All variables included in the model are described in Table 1.

Table 1 Descriptive Statistics of Older Ghanaians (60 plus years) with proportions (\%) of sociodemographic characteristics, health status, and lifestyle activities

\begin{tabular}{|c|c|c|c|c|c|}
\hline Variables & \multirow[t]{2}{*}{$\begin{array}{l}\text { Frequency } \\
(n=1408)\end{array}$} & \multicolumn{2}{|l|}{ Percentage } & \multicolumn{2}{|l|}{ Percentage } \\
\hline \multirow[b]{2}{*}{ Age $(>=60$ years $)$} & & Unweighted & Weighted & Unweighted Mean & $\begin{array}{l}\text { Weighted } \\
\text { Mean }\end{array}$ \\
\hline & & & & 71.26 & 71.23 \\
\hline $\begin{array}{l}\text { Gender } \\
\text { Male } \\
\text { Female }\end{array}$ & $\begin{array}{l}647 \\
761\end{array}$ & $\begin{array}{l}45.95 \\
54.05\end{array}$ & $\begin{array}{l}49.31 \\
50.69\end{array}$ & & \\
\hline $\begin{array}{l}\text { R/ship status } \\
\text { Partner } \\
\text { No Partner }\end{array}$ & $\begin{array}{l}663 \\
745 \\
\end{array}$ & $\begin{array}{l}47.09 \\
52.91\end{array}$ & $\begin{array}{l}52.56 \\
47.44\end{array}$ & & \\
\hline $\begin{array}{l}\text { Residence } \\
\text { Urban } \\
\text { Rural }\end{array}$ & $\begin{array}{l}607 \\
801\end{array}$ & $\begin{array}{l}43.11 \\
56.89\end{array}$ & $\begin{array}{l}43.57 \\
56.43\end{array}$ & & \\
\hline $\begin{array}{l}\text { Education level } \\
\text { High } \\
\text { Low }\end{array}$ & $\begin{array}{l}284 \\
1124 \\
\end{array}$ & $\begin{array}{l}20.17 \\
79.83\end{array}$ & $\begin{array}{l}22.62 \\
77.38 \\
\end{array}$ & & \\
\hline $\begin{array}{l}\text { Health insurance } \\
\text { Yes } \\
\text { No }\end{array}$ & $\begin{array}{l}709 \\
699 \\
\end{array}$ & $\begin{array}{l}50.36 \\
49.64\end{array}$ & $\begin{array}{l}49.69 \\
50.31 \\
\end{array}$ & & \\
\hline $\begin{array}{l}\text { Meets needs } \\
\text { Yes } \\
\text { No }\end{array}$ & $\begin{array}{l}419 \\
989 \\
\end{array}$ & $\begin{array}{l}29.76 \\
70.24\end{array}$ & $\begin{array}{l}31.30 \\
68.70 \\
\end{array}$ & & \\
\hline $\begin{array}{l}\text { Needs care } \\
\text { Yes } \\
\text { No }\end{array}$ & $\begin{array}{l}46 \\
1362 \\
\end{array}$ & $\begin{array}{l}3.27 \\
96.73\end{array}$ & $\begin{array}{l}3.36 \\
96.64\end{array}$ & & \\
\hline $\begin{array}{l}\text { Health status } \\
\text { Good } \\
\text { Poor }\end{array}$ & $\begin{array}{l}1070 \\
338\end{array}$ & $\begin{array}{l}75.99 \\
24.01\end{array}$ & $\begin{array}{l}75.44 \\
24.56\end{array}$ & & \\
\hline Fruit servings & & & & 2.38 & 2.36 \\
\hline Vegetable servings & & & & 2.07 & 2.09 \\
\hline Moderate work & & & & 0.64 & 0.62 \\
\hline Moderate exercise & & & & 0.13 & 0.14 \\
\hline Walking/biking & & & & 0.75 & 0.73 \\
\hline Leisure hours & & & & 3.11 & 3.11 \\
\hline Care use rate & & & & 2.97 & 2.90 \\
\hline
\end{tabular}

\section{RESULTS}

The study investigated the relationship between outpatient care use rate and sociodemographic factors, socioeconomic factors, health, and especially lifestyle activities. Table 2 shows the results of the negative binomial

regression model 1 with care use rate as the outcome variable. Apart from gender and health insurance, other variables included in the model were found to have statistically significant associations with the outcome variable. 


\section{Original Article}

For each variable association reported, all other variables are assumed to have been held constant in the model.

Table 2 Results of the negative binomial regression with care use rate as the outcome variable

\begin{tabular}{|c|c|c|c|}
\hline Variables & $\begin{array}{l}\text { Parameter } \\
\text { Estimate }\end{array}$ & $\begin{array}{l}\text { Exp. Esti- } \\
\text { mate }\end{array}$ & SE \\
\hline Age & $-0.0020^{* * *}$ & 0.9980 & 0.0003 \\
\hline $\begin{array}{l}\text { Gender }(\text { ref }=\text { female }) \\
\text { Male }\end{array}$ & -0.0037 & 0.9963 & 0.0056 \\
\hline $\begin{array}{l}R / \text { status }(\text { ref }=\text { no partner }) \\
\text { Partner }\end{array}$ & $-0.0119 *$ & 0.9882 & 0.0055 \\
\hline $\begin{array}{l}\text { Residence (ref = Urban) } \\
\text { Rural }\end{array}$ & $-0.0801 *$ & 0.9230 & 0.0045 \\
\hline $\begin{array}{l}\text { Education level }(\text { ref }=\text { Low }) \\
\text { High }\end{array}$ & $0.1541 * * *$ & 1.1667 & 0.0075 \\
\hline $\begin{array}{l}\text { Health Insurance (ref = } \\
\text { Uninsured) } \\
\text { Insured }\end{array}$ & 0.0082 & 1.0082 & 0.0046 \\
\hline $\begin{array}{l}\text { Health Status }(\text { ref = Poor }) \\
\text { Good }\end{array}$ & $-0.1584 * * *$ & 0.8535 & 0.0075 \\
\hline $\begin{array}{l}\text { Care Need }(\text { ref }=\text { No }) \\
\text { Yes }\end{array}$ & $-0.1115 * * *$ & 0.8945 & 0.0095 \\
\hline $\begin{array}{l}\text { Meets needs }(\text { ref }=\text { No }) \\
\text { Yes }\end{array}$ & $0.0509 * * *$ & 1.0522 & 0.0056 \\
\hline Vegetable servings & $-0.0830 * * *$ & 0.9203 & 0.0025 \\
\hline Fruit servings & $-0.0033^{*}$ & 0.9967 & 0.0014 \\
\hline $\begin{array}{l}\text { Moderate work }(r e f=N o) \\
\text { Yes }\end{array}$ & $-0.2049 * * *$ & 0.8148 & 0.0042 \\
\hline $\begin{array}{l}\text { Moderate exercise (ref }= \\
\text { No) } \\
\text { yes }\end{array}$ & $-0.4010 * * *$ & 0.6696 & 0.0052 \\
\hline $\begin{array}{l}\text { Walking/biking }(\text { ref }=\text { No }) \\
\text { Yes }\end{array}$ & $-0.0436 * * *$ & 0.9573 & 0.0055 \\
\hline Leisure hours & $0.0194 * * *$ & 1.0196 & 0.0009 \\
\hline
\end{tabular}

Notes: R/status = Relationship status, Exp. =Exponentiation; $\mathrm{SE}=$ standard error; $* \mathrm{p}<.05 . * * \mathrm{p}<.01 . * * * \mathrm{p}<.001$. ref $=$ reference, $n=$ 132727 instead of 1408 after multiple imputations

Age (60 years and above) predicted outpatient care utilization rate. A year increase in age decreases the rate of outpatient care utilization by less than $1 \%$. Older Ghanaians with partners have a $1 \%$ lower rate of outpatient care use than those without partners, and those who reside in rural areas have about $8 \%$ lower rate of outpatient care utilization than those in urban areas. In terms of education level, those who have high education have about $17 \%$ higher rate of outpatient care use than those with low education.

The rate of outpatient care utilization is about $15 \%$ lower for older adults who reported they have good health status than those with poor health status. Also, older adults who reported that they need care have about $11 \%$ lower outpatient care use rate than those who reported not to need care. Poverty is an important predictor of outpatient care utilization rate. Those who have money to meet their needs have about $5 \%$ higher outpatient care use rate than those who do not have enough money to meet their needs.

In terms of lifestyle indicators, among older Ghanaians in the study, a unit increase in the number of vegetable servings per day results in about $8 \%$ lower rate of outpatient care utilization. Similarly, a unit increase in the number of fruit servings per day results in less than $1 \%$ lower rate of outpatient care use among the older adults. These associations support hypothesis 1. Additionally, those who engage in moderate work have about $19 \%$ lower rate of outpatient care use than those who do not engage in moderate work. Moderate exercise was found to have the strongest effect on predicting outpatient care use.

Those who engage in moderate exercise have about $30 \%$ lower outpatient care utilization rate than those who do not do moderate exercise. Older adults in the study who take walks or ride their bicycles have about $4 \%$ lower rate of outpatient care use than those who do not. The effect of doing moderate work and exercise support our second hypothesis. Also, sedentary lifestyle in the form of sitting down for too long doing nothing productive, such as watching television or listening to the radio increased outpatient care use rate. A unit increase in the hours spent sitting idle also referred to as leisure hours increases the rate of outpatient care utilization by about $2 \%$. This supports our third hypothesis.

\section{DISCUSSION}

The findings of this study and their interpretation are underpinned by the Behavioral Model for Vulnerable Populations ${ }^{25}$, which is important in identifying and explaining factors that contribute to healthcare utilization among vulnerable groups like the older population in Ghana. These older adults are at high risk of chronic diseases (poor health), which is a need factor. Combined with predisposing factors such as education and rural residence, and enabling factors such as poverty and lifestyle activities, there are indications that these factors influence outpatient care use among older Ghanaians. ${ }^{25,26,27}$

Our findings show that among the older adults, increase in age reduces outpatient care utilization rate by less than $1 \%$. The direction of the relationship is surprising since increased age increases poor health outcomes ${ }^{8,10,12}$, which in turn should increase outpatient care use rate. An explanation for this negative association with negligible magnitude of effect may be because the study controlled for place of residence, education, poverty, and health status. 


\section{Original Article}

Older Ghanaians reside more in rural areas, and they tend to be poor, with low education, and high risk of chronic diseases.

These factors influence outpatient care use rate and controlling for them may be the reason why age itself, although statistically associated, has a very little effect magnitude. Indeed, residence in rural Ghana may reflect a lack of access to and/or difficulty obtaining outpatient care more so than a reduction in need.

In terms of other sociodemographic factors that influence outpatient care utilization rate, having a partner reduces outpatient care use rate, and this is consistent with studies that mention that having social support can reduce the risks of poor health outcomes. ${ }^{36,37}$ Those in rural areas in the study have lower outpatient care utilization rate than those in urban areas. One explanation for these findings are that although rural older dwellers have higher odds of chronic diseases than older adults in urban areas ${ }^{2,8}$, they may not have the resources to access modern healthcare, or they may rely heavily on traditional medical practices. ${ }^{5}$ Also, those who need care or caregiving are less likely to use outpatient care. There is a possible cultural explanation for this finding. In a typical African family, family members provide support and those who do not have caregivers (need caregiving) may be because they lack family support, which may result in little or no assistance towards accessing outpatient care when needed.

Socioeconomic status influences ability to access healthcare. According to our study, having high education level and having enough money to meet needs, which is an indicator of participants' poverty levels, influence outpatient care utilization rate? The poorer older adults are, the less likely they are able to utilize outpatient care. This is consistent with other studies that mention financial resource as an important predictor of one's ability to access healthcare. ${ }^{2,3}$ Also, older adults with high education are more likely than those with low education to use outpatient care. Socioeconomic situations among these older adults may mean that poorer older adults are perhaps illiterate or have low education, and our descriptive statistics show that about $80 \%$ of the participants have low education.

Affordability of healthcare services is important in this setting given that the cost of healthcare services is paid out-of-pocket at the point-of-use and given the inequity in coverage of the existing health insurance scheme in Ghana. ${ }^{4,5,6,38,39}$ In addition, the important role of socioeconomic status on healthcare utilization reported in our study aligns with the evidence from other studies in different settings. ${ }^{40,41}$ As such, it is possible that lifestyle factors like exercise and vegetable consumption are partly intentional, and partly unintentional strategies used by this older population to manage their health outcomes and the cost of healthcare services.

The study found that fruits and vegetables consumption lower the rate of outpatient care utilization. There are studies that emphasize the importance of modifying lifestyles like nutrition and physical activities for better health outcomes among older adults. ${ }^{14,22}$ From our study, the effect of fruits and vegetable consumption on outpatient care utilization is consistent with the findings from previous studies that have investigated the impact of healthy eating on health status and healthcare utilization rate. ${ }^{15,16,41,42}$ Another US-based study on the effect of fruit and vegetable consumption in middle-age on Medicare utilization in older-age reported that higher vegetable consumption was associated with lower Medicare charges. ${ }^{42}$ Thus, reduced poor health outcomes resulting from healthier lifestyle may reduce the financial burdens of healthcare cost on older Ghanaians and their families. ${ }^{17}$

Engaging in physical activities like exercising reduces the risk of poor health outcomes, which also lowers the risk of functionality issues among aging older adults. $18,19,20$ This is similar to our findings. The rate of outpatient care use is lower for those who do moderate exercise, those who do moderate work, those who walk/bike, than those who do not do these activities. Similar to Keeler et al.'s (1989) study, it was found that increased sitting or leisure hours termed sedentary lifestyle increases the rate of outpatient care use because of the resulting poor health outcomes.

Importantly, the protective effect of staying active through moderate exercise and work seen in our study might be an unintended benefit from the poverty and deprivation rates in this setting, especially in the rural areas in Ghana. ${ }^{43}$ The low access and affordability of motorized or vehicular means of transportation among this population may mean more physical activity through walking is expected. Another possible explanation is that most of the work older adults are exposed to might be more physical than intellectual. Therefore, doing moderate work may be a way to stay active, which may reduce risks of poor health outcomes.

\section{Study Limitations and Strengths}

The absence of data on the specific reason for outpatient care utilization or diagnosis from such visits limits our ability to identify the specific target of the different lifestyle factors that significantly predicted the outcome. Also, the lifestyle factors in this study were self-reported, so they may have been under or over reported. 
However, self-report remains the most feasible way of measuring the lifestyle factors in population health studies, and its validity is consistently acceptable. ${ }^{44,45}$

The study is a cross-sectional type, and as such the direction of the relationships (causality) observed cannot be confirmed. Another limitation is the level of missing observations, but this was addressed using a fully conditional statement approach in multiple imputation method. Nevertheless, follow-up data collections should emphasize more complete data completion among respondents.

\section{CONCLUSION}

To the best of our knowledge, this study is the first to investigate the effect of lifestyle factors like exercise and healthy diets on outpatient care utilization among older adults in a developing country. Regardless of whether they are intended, moderate exercise, moderate work, walking/biking, less sitting for long periods, and increase in consumption of fruits and vegetables have the ability to reduce the use of outpatient care services in older adults in Ghana. Future work should examine more detailed links between specific outpatient services uses and lifestyle factors such as those examined here.

\section{ACKNOWLEDGEMENT}

We acknowledge the support of Dr. Jonathon Vivoda of Miami University, Ohio, USA, for always finding the time to discuss some aspects of the study. We are grateful to the World Health Organization (sponsor) for the Study on Global Ageing and Adult Health (SAGE), and the WHO-SAGE principal investigators, Drs. Somnath Chatterji and Paul Kowal. We are also grateful to InterUniversity Consortium for Political and Social Research (ICPSR), Michigan, USA, for making the WHO-SAGE data available to us.

\section{REFERENCES}

1. Hewlett, S. A., Yawson, A. E., Calys-Tagoe, B. N., Naidoo, N., Martey, P., Chatterji, S., Biritwum, R. B. (2015). Edentulism and quality of life among older Ghanaian adults. BMC Oral Health. 2015;15(1): 1-9. https://doi.org/10.1186/s12903015-0034-6

2. Saeed, B. I., Xicang, Z., Yawson, A. E., Nguah, S. B., \& Nsowah-Nuamah, N. N. Impact of socioeconomic status and medical conditions on health and healthcare utilization among aging Ghanaians. $B M C$ Public Health. 2015; (15): 276. https://doi.org/10.1186/s12889-015-1603-y

3. Parmar, D., Williams, G., Dkhimi, F., Ndiaye, A., Asante, F. A., Arhinful, D. K., \& Mladovsky, P. Enrolment of older people in social health protection programs in West Africa - Does social exclusion play a part? Soc Sci Med. 2014;(119): 36-44. https://doi.org/10.1016/j.socscimed.2014.08.011

4. Akazili, J., Welaga, P., Bawah, A., Achana, F. S., Oduro, A., Awoonor-Williams, J. K., Phillips, J. F. Is Ghana's pro-poor health insurance scheme really for the poor? Evidence from Northern Ghana. BMC Health Serv Res. 2014;14(1): 637. https://doi.org/10.1186/s12913-014-0637-7

5. Apt, N. Older people in rural Ghana: Health and health seeking behaviours. In P. Maharaj (Ed.), Aging and Health in Africa (pp. 103-119). Boston, MA: Springer US; 2013. https://doi.org/10.1007/978-1-4419-8357-2_5

6. Peters, D. H., Garg, A., Bloom, G., Walker, D. G., Brieger, W. R., \& Rahman, M. H. Poverty and access to health care in developing countries. Ann N Y Acad Sci. 2008; 1136(1): 161-171. https://doi.org/10.1196/annals.1425.011

7. Alhassan, R. K., Nketiah-Amponsah, E., \& Arhinful, D. K. A review of the national health insurance scheme in Ghana: What are the sustainability threats and prospects? PLoS One. 2016; 11(11): e0165151. https://doi.org/10.1371/journal.pone.0165151

8. World Health Organization. Ghana country assessment report on ageing and health. 2014; [cited 2017 May 12]. Available from http://apps.who.int/iris/handle/10665/126341

9. Zaney, G., D. Promoting a healthier, secure aging. 2018; [cited 2018 Jan 19]. Available from: http:/www.ghana.gov.gh/index.php/media-center/features/1966-promoting-a-healthier-secure-ageing

10. Ghana Statistical Service. The elderly in Ghana. 2013; [cited 2017 Mar 30]. Available from:http:/www.statsghana.gov.gh/docfiles/publications/2010phc the elderly in Gh.pdf

11. Mba, C., J. Population ageing in Ghana: Research gaps and the way forward. J Aging Res. 2010; vol. 2010, Article ID 672157, 1-8. https://doi.org/10.4061/2010/672157

12. Tawiah, E., O. Population ageing in Ghana: A profile and emerging issues. Etude Popul Afr. 2011; 25(2): 623-645.

13. Ayernor, P. Diseases of ageing in Ghana. Ghana Med J. 2012; 46(2 Suppl.): 18-22.

14. Minicuci, N., Biritwum, R. B., Mensah, G., Yawson, A. E., Naidoo, N., Chatterji, S., \& Kowal, P. Sociodemographic and socioeconomic patterns of chronic non-communicable disease among the older adult population in Ghana. Glob Health Action. 2014; 7(1): 21292. https://doi.org/10.3402/gha.v7.21292

15. Liu, S., Manson, J. E., Lee, I.-M., Cole, S. R., Hennekens, C. H., Willett, W. C., \& Buring, J. E. Fruit and vegetable intake and risk of cardiovascular 
disease: The women's health study. Am J Clin Nutr. 2000; 72(4): 922-928. https://doi.org/10.1093/ajen/72.4.922

16. Campbell, M. K., Demark-Wahnefried, W., Symons, M., Kalsbeek, W. D., Dodds, J., Cowan, A., McClelland, J. W. Fruit and vegetable consumption and prevention of cancer: The black churches united for better health project. Am J Public Health. 1999; 89(9): 1390-1396.

https://doi.org/10.2105/AJPH.89.9.1390

17. Keeler, E. B., Manning, W. G., Newhouse, J. P., Sloss, E. M., \& Wasserman, J. The external costs of a sedentary life-style. Am J Public Health. 1989; 79(8): 975-981. https://doi.org/10.2105/AJPH.79.8.975

18. Drewnowski, A., \& Evans, W. J. Nutrition, physical activity, and quality of life in older adults summary. J Gerontol A Biol Sci Med Sci. 2001; 56(suppl_2): 89-94 https://doi.org/10.1093/gerona/56.suppl 2.89

19. McPhee, J. S., French, D. P., Jackson, D., Nazroo, J., Pendleton, N., \& Degens, H. Physical activity in older age: Perspectives for healthy ageing and frailty. Biogerontology. 2016; 17: 567-580. https://doi.org/10.1007/s10522-016-9641-0

20. Taylor, D. Physical activity is medicine for older adults. Postgrad Med J. 2014; 90(1059): 26-32. https://doi.org/10.1136/postgradmedj-2012-131366

21. Bazzano, L. A., He, J., Ogden, L. G., Loria, C. M., Vupputuri, S., Myers, L., \& Whelton, P. K. Fruit and vegetable intake and risk of cardiovascular disease in US adults: The first national health and nutrition examination survey epidemiologic follow-up study. Am J Clin Nutr. 2002; 76(1): 93-99. https://doi.org/10.1093/ajen/76.1.93

22. Warburton, D. E. R., Nicol, C. W., \& Bredin, S. S. D. Health benefits of physical activity: The evidence. CMAJ 2006;174(6):801-809. https://doi.org/10.1503/cmaj.051351

23. Tagoe, H. A., \& Dake, F. A. Healthy lifestyle behaviour among Ghanaian adults in the phase of a health policy change. Global Health. 2015; 7(7): 1-9. https://doi.org/10.1186/1744-8603-7-7

24. Aganiba, B. A., Owusu, W. B., Steiner-Asiedu, M., $\&$ Dittoh, S. Association between lifestyle and health variables with nutritional status of the elderly in the northern region of Ghana. Afr J Food Agric Nutr Dev. 2015; 15(4): 10198-10216.

25. Gelberg, L., Andersen, R. M., \& Leake, B. D. The behavioral model for vulnerable populations: Application to medical care use and outcomes for homeless people. Health Serv Res. 2000; 34(6): 12731302.

26. Oser, C. B., Bunting, A. M., Pullen, E., \& StevensWatkins, D. African American female offender's use of alternative and traditional health services after re- entry: Examining the behavioral model for vulnerable populations. J Health Care Poor Underserved. 2016; 27(2): 120-148.

https://doi.org/10.1353/hpu.2016.0052

27. Stein, J. A., Andersen, R., \& Gelberg, L. Applying the Gelberg-Andersen behavioral model for vulnerable populations to health services utilization in homeless women. J Health Psychol. 2016; 12(5): 791-804.

https://doi.org/10.1177/1359105307080612

28. Chatterji, S., \& Kowal, P. WHO Study on Global AGEing and Adult Health (SAGE): Wave 1, 20072010. Ann Arbor, MI: Inter-university Consortium for Political and Social Research [distributor], 2013. https://doi.org/10.3886/ICPSR31381.v1

28. Allison, P., D. Logistic regression using SAS: Theory and application. 2 nd ed. Cary, NC: SAS Institute; 2012.

29. Hilbe, J. M. Negative binomial regression. New York, NY: Cambridge University Press; 2007.

30. Bartlett, J. W., Seaman, S. R., White, I. R., \& Carpenter, J. R. Multiple imputation of covariates by fully conditional specification: Accommodating the substantive model. Stat Methods Med Res. 2015; 24(4): $462-487$. https://doi.org/10.1177/0962280214521348

31. White, I., R., Royston, P., \& Wood, A. M. (2011). Multiple imputation using chained equations: Issues and guidance for practice. Stat Med. 2011; 30(4): 377-399. https://doi.org/10.1002/sim.4067

32. Mackinnon, A. The use and reporting of multiple imputation in medical research - a review. $J$ Intern Med. 2010; 268(6): 586-593. https://doi.org/10.1111/j.1365-2796.2010.02274.x

33. Kang, $H$. The prevention and handling of the missing data. Korean J Anesthesiol. 2013; 64(5): 402-406. https://doi.org/10.4097/kjae.2013.64.5.402

34. Allison, P., D. Missing data. Sage Publications; 2002.

35. University of California Los Angeles Institute for Digital and Research Education. Multiple imputation in SAS part 1. [cited 2018 Nov 13]. Available from: https://stats.idre.ucla.edu/sas/seminars/multiple-imputation-in-sas/mi new 1/

36. Hernandez, D. C., Reitzel, L. R., Wetter, D. W., \& McNeill, L. H. Social support and cardiovascular risk factors among black adults. Ethn Dis. 2014; 24(4): 444-450.

37. Reblin, M., \& Uchino, B. N. Social and emotional support and its implication for health. Curr Opin Psychiatry. 2008; 21(2): 201-205. https://doi.org/10.1097/YCO.0b013e3282f3ad89

38. Akazili, J., McIntyre, D., Kanmiki, E. W., Gyapong, J., Oduro, A., Sankoh, O., \& Ataguba, J. E. Assessing the catastrophic effects of out-of-pocket 
healthcare payments prior to the uptake of a nationwide health insurance scheme in Ghana. Glob health action. 2017, 10(1): 1289735.

39. Dalinjong, P., A., Wang, A., Y., Homer, C. S. The operations of the free maternal care policy and out of pocket payments during childbirth in rural Northern Ghana. Health Econ Rev. 2017; 7(1): 41.

40. Roy, K., Chaudhuri, A. Influence of socioeconomic status, wealth and financial empowerment on gender differences in health and healthcare utilization in later life: Evidence from India. Soc Sci Med. 2008; 66(9): 1951-1962.

41. Sortsø, C., Lauridsen, J., Emneus, M., Green, A., \&amp; Jensen, P. B. Socioeconomic inequality of diabetes patients' health care utilization in Denmark. Health Econ Rev. 2017; 7(1): 21.

42. Sharma, S., Vik, S., \& Kolonel, L. N. Fruit and vegetable consumption, ethnicity and risk of fatal ischemic heart disease. J Nutr Health Aging. 2014; 18(6): 573-578.
42. Daviglus, M. L., Liu, K., Pirzada, A., Yan, L. L., Garside, D. B., Wang, R., \& Greenland, P. Relationship of fruit and vegetable consumption in middleaged men to Medicare expenditures in older age: The Chicago Western Electric Study. J Am Diet Assoc. 2005; 105(11): 1735-1744.

43. World Bank. Poverty reduction in Ghana: Progress and challenges. 2015 [cited 2018 Aug 10]; Available from: $\quad$ http://www.worldbank.org/en/country/ghana/publication/poverty-reduction-ghana-progress-challenges

44. Vargas, C. M., Burt, V. L., Gillum, R. F., \& Pamuk, E. R. Validity of self-reported hypertension in the National Health and Nutrition Examination Survey III, 1988-1991. Prev med. 1997; 26(5): 678-685.

45. Spencer, E. A., Appleby, P. N., Davey, G. K., \&amp; Key, T. J. Validity of self-reported height and weight in 4808 EPIC-Oxford participants. Public Health Nutr. 2002; 5(4): 561-565. 